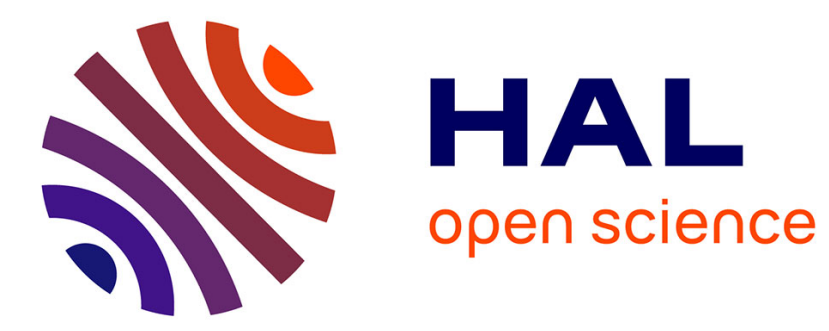

\title{
Application of multi-objective nonlinear optimization technique for coordinated ramp-metering
}

\author{
Habib Haj Salem, Nadir Farhi, Jean Patrick Lebacque
}

\section{To cite this version:}

Habib Haj Salem, Nadir Farhi, Jean Patrick Lebacque. Application of multi-objective nonlinear optimization technique for coordinated ramp-metering. ICNAAM - International Conference of Numerical Analysis and Applied Mathematics, Sep 2014, Rhodes, France. 3p. hal-01240111

\section{HAL Id: hal-01240111 \\ https://hal.science/hal-01240111}

Submitted on 8 Dec 2015

HAL is a multi-disciplinary open access archive for the deposit and dissemination of scientific research documents, whether they are published or not. The documents may come from teaching and research institutions in France or abroad, or from public or private research centers.
L'archive ouverte pluridisciplinaire HAL, est destinée au dépôt et à la diffusion de documents scientifiques de niveau recherche, publiés ou non, émanant des établissements d'enseignement et de recherche français ou étrangers, des laboratoires publics ou privés. 


\title{
Application of Multi-Objective Nonlinear Optimization Technique For Coordinated Ramp- Metering
}

\author{
HAJ SALEM Habib., FARHI Nadir, LEBACQUE Jean Patrick \\ IFSTTAR/GRETITA, 14-20, Bd Newton, 77447 Marne-La-Vallée Cedex2, France, \\ habib.haj-salem@ifsttar.fr; nadir.frahi@ifsttar.fr; jean-patrick.lebacque@ifsttar.fr,
}

\begin{abstract}
This paper aims at developing a multi-objective nonlinear optimization algorithm applied to coordinated motorway ramp metering. The multi-objective function includes two components: traffic and safety. Off-line simulation studies were performed on A4 France Motorway including 4 on-ramps.
\end{abstract}

Keywords: ramp metering, multi-objective optimal nonlinear control, off line evaluation.

\section{INTRODUCTION AND BACKGROUND}

A number of approaches have been developed in the past for the design of control strategies that involve control measures such as route recommendation via Variable Message Signs (VMS) devices or equipped vehicles, ramp metering, motorway-to-motorway control (MTMC), automatic incident detection (AID), hard lane shoulder etc. Several approaches were investigated including expert systems, fuzzy systems, neural networks, and classical feedback control and optimal control. In general, traffic control systems within corridors or motorway networks have been developed independently for each individual control measure attempting to optimize traffic flow on the motorway or the urban road network or the both components. With respect to the optimal control, the problem formulation was focused on the development of the integrated strategies which take into account simultaneously several control strategies such as ramp metering, MTMC, user's guidance [1], [5], [6]. This global point of view suggests that control measures within the entire network should be designed in an integrated way, or, at least, they should be suitably coordinated during operation, so as to meet the overall objectives. These approaches are very promising. Nevertheless, whatever considered approach, in general, the considered objective function is mainly focused on the traffic index such as minimizing the Total Time Spent index (TTS) in the considered system. In particular, the safety aspect is considered as an indirect cost function and computed during the evaluation process.

This paper is focused on the development of control strategy based on multi-objective index function, including traffic indices and safety and in particular the risk index model. The first part of this paper is dedicated to the development of the risk index modelling. The second part is focalized on the application of the optimal control for the coordinated ramp metering using the multi-objective function. The numerical solution of a formulated large-scale non linear optimal control problem is effectuated by application of a non-linear optimization techniques based on the optimal control theory which is able to deal straightforwardly with nonlinear features. In this paper, we investigate the efficiency of this multi-objective non-linear approach by using a macroscopic multi-model simulation tool namely MAGISTER which is able to simulate traffic flow phenomena in corridor networks of arbitrary topology.

\section{RISK INDEX MODEL BUILDING}

An extensive research has been performed for the risk model building. Based on statistical analysis of extended data base including real-data measurements (traffic volume, occupancy rate and speed) synchronized with the accidents on the ring way of Paris during 5 years. The developed risk index is validated on several motorways around Paris (A6W, A86, A4 etc.) [2].

The considered elementary system is the following: 


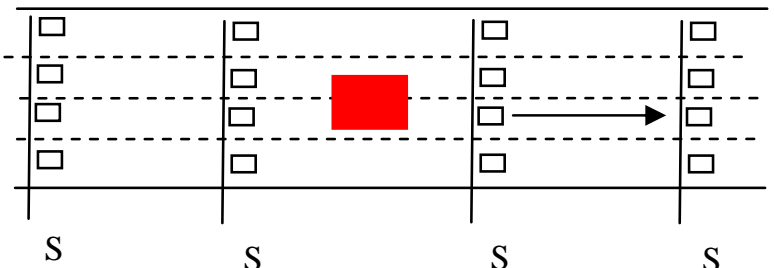

The mathematical equation found reads:

$$
\text { Risk = } \frac{1}{1+\exp \left[\begin{array}{llllll}
-(-7.1677 & +0.2122 & \text { Oc_st1 } & +0.1383 & \text { Oc_st2 } & \\
-0.1061 & \text { Oc_st3 } & -0.2052 & \text { Oc_st4 } & +0.000385 & \text { q_st1 })
\end{array}\right]}
$$

This risk index can be used either off-line as an evaluation index during the evaluation process which leads to the dramatically reduction of the field test periods, or in real-time like safety monitoring tool (e.g. safety user warning system), or a multi-criterion function to be optimized in real time (safety index combined with a traffic index). In this paper, focus is made on the integration of the risk index function in the optimization criteria for coordinated ramp metering strategy. In the final paper, this section will be described in details.

\section{MATHEMATICAL PROBLEM FORMULATION}

Consider a traffic process described by the state equation:

$$
\underline{x}(k+1)=f[\underline{x}(k), \underline{u}(k), \underline{d}(k), k]
$$

Where $\underline{x}(k) \in \mathrm{R}^{\mathrm{n}}, \underline{u}(k) \in \mathrm{R}^{\mathrm{m}}, \underline{d}(k) \in \mathrm{R}^{\mathrm{n}}$ denote the state, control and disturbance vectors respectively. In our study, the state macroscopic variables (the vector $x(k)$ ) includes the densities and speeds in corresponding segments of the motorway network links:

$$
x=\left[\begin{array}{ll}
\rho_{l} & v_{i}
\end{array}\right]^{T}
$$

\section{Non Linear Programming Approach (NLPA)}

Let us consider the equation (2) without $\underline{d}(k)$ which are supposed known.

$$
\underline{x}(k+1)=f[\underline{x}(k), \underline{u}(k), k] \quad, \quad k=0, \ldots, H
$$

With an initial state: $\underline{x}(0)=\underline{x}_{0}$

In MAGISTER platform, the METACOR model is used [3]. In equation (4) , $f$ is supposed to be twice continuous differentiable vector function. The equations relatives to the computation of flows and speeds can be found in [3].

A global control strategy aiming at system optimum minimizes a specific global cost function [5]. This function can be the total travel time spent in the network during a defined time horizon. In this paper, we choose to improve the transport efficiency, by using a cost criterion $J$ that includes two components:

Traffic: Total Time Spent (a) and the waiting time at origins (b) expressed as:

$$
J_{\text {Traf }}=\sum_{k=0}^{H}[\underbrace{T \sum_{l=1}^{L} \sum_{s=1}^{S} \rho_{l, s}(k) \cdot \Delta_{l} \cdot \lambda_{l}}_{(a)}+\underbrace{T \sum_{o=1}^{O} w_{o}(k)}_{(b)}]
$$

Safety index:

$$
J_{\text {safety }}=\sum_{k=0}^{H}\left[\sum_{l=1}^{L} \sum_{s=1}^{S} \operatorname{Risk}(l, s)\right]
$$

Where $H, L, S, O$ denotes respectively the horizon, the number of links, the number of segments in each link, and the number of origins respectively. In equation (5), the terms $\Delta_{l}, \lambda_{l}, w_{O}$ denote the length of the link $l$, the number of lanes of the segment $l$, and the number of vehicles in the queue at origins $o$ respectively. 
The algorithm uses to minimize this cost function $J$ can be any non-linear optimization algorithm such the basic steepest gradient descent or a quasi-newton method (BFGS). In our example, we use a method called RPROP [4], known to be a fast and simple algorithm.

The formulation and a description of a general algorithm will be described in the full paper.

\section{OFF-LINE SIMULATION STUDIES}

The developed optimisation algorithm has been implemented in the kernel of the simulation tool MAGISTER. This means that the developed algorithm can be applied to any corridor network without any specific development.

The particular corridor network considered in this study is in the southern part of the Ile de France motorway network A6W. The test site includes 5 controlled on-ramps and covers $20 \mathrm{~km}$ length. In the following application, we apply a control over all on-ramps. Several simulation runs with realistic demands (based on real data) has been performed by considering the objective function as indicated in equations (5) and (5) $+(6)$. Detailed results will be reported in the final paper.

\section{CONCLUSIONS AND NEXT STEPS}

The application, on the considered network including 5 ramp-metering controls is promising in terms of performances and computational effort. Obtained results will be described in the final paper. The next step consists in expanding this approach in order to make integrated control. Integration means to perform a control of different type of devices such as ramp metering, speed limit and route guidance.

\section{REFERENCES}

1. Haj-Salem, Papageorgiou, M., 1995, Ramp Metering Impact on Urban Corridor Traffic : Field Results. Transportation Research -A. Vol 29A, No.4, pp 303-319.

2. H. Haj Salem,C. Ramananjoana, J.P Lebacque (2006) : Risk Index Model for Real-Time Prediction of Potential traffic Crash on Urban Motorway. Proceedings of the EWGT2006, Advances in Traffic and transportation Systems Analysis, BARI, Italy,

3. Elloumi N. et Papageorgiou M. et Haj-Salem H., 1994, A macroscopic modelling tool for urban corridor. TRISTAN II : TRIennal Symposium on Transportation Analysis. Capri-Italy. Congress Center June, 23-28 1994. Vol I, pp 135-149.

4. M Riedmiller and $\mathrm{H}$ Braun. A direct adaptive method for faster back propagation learning: The RPROP algorithm. In Proceedings of the IEEE International Conference on Neural Networks 1993 (ICNN 93).

5. [5] Papageorgiou, M., Marinaki M., 1995, A Feasible direction algorithm for the numerical solution of optimal control problems. Internal report $\mathrm{N}^{\circ} 1995-4$, Technical University of Crete, Greece..

6. A. Kostialos and M. Papageorgiou, Motorway Network Traffic Control Systems, 2004. European Journal of Operational Research, vol.152, pp.321-333. 